\title{
A REDE DE ECONOMIA SOLIDÁRIA EM SANTA CATARINA: TRAJETÓRIA DO FÓRUM CATARINENSE DE ECONOMIA SOLIDÁRIA (FCES)
}

\author{
Elisete Gesser Della Giustina da Correggio ${ }^{1}$ \\ elisete.dacorreggio@gmail.com
}

\author{
Sandra Schlichting ${ }^{2}$ \\ sandras.movimento@gmail.com
}

\begin{abstract}
Resumo
A economia solidária (ES) é no Brasil um movimento, cuja articulação gerou a criação de um fórum nacional, bem como de uma secretaria específica, vinculada ao Ministério do Trabalho. Em Santa Catarina a economia solidária avançou na sua articulação e tem buscado avançar em sua organização com a constituição do Fórum Catarinense de Economia Solidária. O presente artigo apresenta a experiência da constituição e fortalecimento do Fórum Catarinense de Economia Solidária bem como a sua relevância e seus desafios no processo de construção e de empoderamento da rede de economia solidária no estado de Santa Catarina. A metodologia utilizada foi uma pesquisa nos principais documentos de registros de atividades e dos relatórios do Fórum Catarinense de Economia Solidária (FCES) no que tange às atividades de disseminação, organização e capacitação em ES, bem como outras leituras que contribuíram para uma melhor compreensão do objeto de estudo.
\end{abstract}

Palavras-chave: Economia Solidária; Fórum; Movimentos Sociais; Redes; Sociedade Civil.

\section{THE NETWORK OF SOLIDARITY ECONOMY IN SANTA CATARINA: TRAJECTORY OF THE CATARINIAN FORUM FOR SOLIDARITY ECONOMY (FCES)}

\begin{abstract}
The Solidarity Economy (ES) is a movement in Brazil, whose articulation has led to the creation of a national forum, as well as a specific secretariat, linked to the Ministry of Labor. In Santa Catarina the solidary economy has advanced in its articulation and has tried to advance in its organization with the constitution of the Catarinense Forum of Solidary Economy. This article presents the experience of the constitution and strengthening of the Santa Catarina Solidarity Economy Forum as well as its relevance and challenges in the process of building and empowering the solidarity economy network in the state of Santa Catarina. The methodology used was a research on the main activity records documents and the reports of the Santa Catarina Solidarity Economy Forum (FCES) regarding the dissemination, organization and training activities in ES, as well as other readings that contributed to a better understanding of the study object.
\end{abstract}

Keywords: Solidarity economy; Forum; Social movements; Networks; Civil society.

\footnotetext{
${ }^{1}$ Universidade do Sul de Santa Catarina, integrante do Núcleo de Pesquisa em transformação no Mundo do Trabalho (TMT) da Universidade Federal de Santa Catarina, professora da rede estadual.
}

2

P2P \& INOVAÇÃO, Rio de Janeiro, v. 5 n. 1, Ed. Especial, p.73-87, 2018. 


\section{INTRODUÇÃO}

A economia solidária é outro modo de produção, cujos princípios básicos são a propriedade coletiva ou associada do capital o direito à liberdade individual. (Paul Singer)

A origem e o desenvolvimento da economia solidária no estado de Santa Catarina não diferem do que ocorreu e vem ocorrendo no cenário nacional. Ou seja, não se trata de um movimento ou descoberta do início desse novo milênio.

Nos anos oitenta, muitos projetos desenvolvidos por setores do movimento popular e pastorais sociais, nas chamadas comunidades eclesiais de base, desenvolveram ações comunitárias de geração de trabalho e renda, conhecidos como Projetos Alternativos Comunitários (PACs). Eram experiências - em sua maioria nas periferias de centros urbanos - que se pautavam não somente na geração de renda. $O$ eixo central era o conceito de construção da cidadania. Então, essas organizações, tentando atender as demandas concretas do público alvo, desenvolviam toda a temática relacionada à cidadania a partir da geração de trabalho e renda, cujo princípio norteador se pautava na transformação das relações humanas, comunitárias e sociais, priorizando a centralidade do ser humano.

No campo, aconteceu fenômeno muito semelhante. Também a partir dos chamados grupos de reflexão, da dinâmica das comunidades eclesiais de base, ou mesmo do novo sindicalismo, agricultores familiares começaram a se debruçar, discutir e buscar coletivamente alternativas para seus problemas também na organização da produção, da comercialização e do crédito. Esse é o elemento novo que o campo trás, a democratização do acesso ao crédito como ferramenta de desenvolvimento socioeconômico, através de cooperativas de crédito. Surgem, assim, as experiências coletivas de agroindústrias familiares, muito comuns no oeste catarinense, ou mesmo no sul do estado.

Mais recentemente todo esse movimento vem ganhando corpo em virtude do cenário de desemprego estrutural. São empreendimentos que se formam a partir da organização coletiva de trabalhadores/as em empreendimentos que emergem da organização autogestionária de ex-empregados/as em empresas falidas ou em processo falimentar.

Se observarmos a trajetória, dos grupos que desenvolveram alternativas de geração de trabalho e renda em resposta ao aumento do desemprego urbano causado pela estagnação 
econômica e pela reestruturação produtiva, de grupos que buscam nas atividades econômicas associativas alternativas ao empreendedorismo neoliberal individualista... vamos descobrir que se trata de um processo não linear de construções e desconstruções do que hoje se elabora teoricamente como sendo economia solidária.

Segundo Singer, (1997, p. 10) a economia solidária compreende:

[...] todas as formas de organizar a produção, a distribuição e o crédito por princípios solidários. A ideia básica é assegurar a cada um mercado para seus produtos e uma variedade de economias externas, de financiamento a orientação técnica, legal, contábil, etc., através da solidariedade entre produtores autônomos de todos os tamanhos e tipos.

As discussões acerca das iniciativas vinculadas à economia solidária têm crescido nas últimas décadas, impulsionadas pelo processo de reestruturação produtiva; reflexo das mudanças no mundo do trabalho que vêm se estruturando no ideário do projeto neoliberal.

Segundo Magalhães, (2000, p. 2):

[...] um novo padrão de acumulação capitalista começa a se esboçar a partir da década de 70 e transformar profundamente a estrutura dos sistemas de produção, as relações de trabalho e o papel do Estado em todo o mundo, a globalização e a inovação tecnológica, e a partir daí a constituição de um novo patamar de competitividade, forçam a reorganização dos sistemas produtivos. A descentralização da produção, a terceirização e a subcontratação, além de reduzir custos, são estratégias de adequação a um novo mercado.

A chamada "globalização", que é marcada pela mundialização da produção, do consumo, da cultura, pela superação das barreiras geográficas trazidas pelos avanços nos meios de comunicação e descobertas tecnológicas, também é marcada pelo impacto negativo na vida cotidiana das pessoas, caracterizando-se pelo desemprego, subemprego, pelo empobrecimento, pela dificuldade de acessar a satisfação das necessidades básicas, pela exclusão no uso-fruto da riqueza produzida, exclusão no acesso às informações, exclusão aos direitos sociais.

Theis (1999, p. 3) elucida essa análise ao afirmar que:

[...] as consequiências sociais da reestruturação econômica encontram expressão no crescimento da pobreza. Estima-se que o número de pessoas no Brasil excluídas de qualquer benefício do desenvolvimento chegue a 32 milhões. O crescimento da pobreza resulta do aumento das taxas de desemprego, da informalização desenfreada (de uma população economicamente ativa de aproximadamente 64 milhões de trabalhadores, apenas 49 milhões estão empregados), da redução do poder de compra do salário mínimo, da forte concentração de renda, da redução de oferta de produtos básicos. 
Sendo assim, a atuação do Estado limita-se às políticas focalizadas, seletivas e compensatórias, destinadas a uma coletividade de excluídos, contudo descaracterizando-se de seu aspecto universal e redistributivo. Essa redução do papel do Estado é um dos pilares fundamentais do neoliberalismo que se baseia na abertura de mercado e financeirização tendo como consequência disto a limitação de direitos sociais coletivamente conquistados e, consequentemente, um afastamento da democracia (tanto a liberal quanto a social).

Diante deste contexto, as iniciativas de geração de trabalho e renda com a perspectiva da economia solidária, ressurgem com uma das formas de enfrentamento, de reação, de resistência ao empobrecimento da população.

A Economia Popular Solidária, se fortalece como um dos atores que constroem, em médio prazo, uma verdadeira política nacional de enfrentamento da pobreza, amparada numa sólida opção por um modelo de desenvolvimento endógeno e uma conseqüente inserção ativa na mundialização (LISBOA, 2000, p. 54).

Percebe-se assim que a economia solidária, no Brasil e em Santa Catarina, compreende uma diversidade de práticas econômicas e sociais organizadas sob a forma de cooperativas, associações, empresas autogestionárias, redes de cooperação, complexos cooperativos, entre outros, que realizam atividades de produção de bens de consumo, prestação de serviços, finanças solidárias, trocas, comércio justo e consumo solidário.

As experiências que vêm se desenvolvendo desde a década de oitenta do século passado são uma estratégia de enfrentamento da sociedade civil à crise do mundo do trabalho e ao aumento da exclusão social de grande parcela de trabalhadores/as.

Atualmente, a economia solidária vem crescendo de maneira muito rápida, não apenas no Brasil, mas também em diversos outros países. O mapeamento - SIES - sistema de identificação e registro de informações dos empreendimentos econômicos solidários e das entidades de apoio, assessoria e fomento à economia solidária no Brasil, realizado em 2005 e ainda em andamento já apontou que 70\% dos empreendimentos solidários mapeados no Brasil foram criados entre 1990 e 2005 e que deles participam um milhão e duzentos e cinquenta mil trabalhadores/as, por meio de múltiplas formas de organização, nas quais predominam as associações, com 54\%, vindo em seguida os grupos informais com $33 \%$ e as cooperativas com $11 \%$. Das atividades desenvolvidas pela economia solidária resulta extensa variedade de produtos e serviços em todo território nacional.

A economia solidária avançou recentemente na sua articulação e têm buscado avançar em sua organização com a constituição de Fóruns, em especial o Fórum Brasileiro de ES, redes de produção e comercialização, organizações de representação de seus participantes, 
etc. Isto tem permitido fortalecer as ações de elaboração coletiva e a expressão conjunta de concepções e propostas, bem como de reorganização de fluxos econômicos e culturais, com vistas a fortalecer os processos solidários de consumo, comercialização, intercâmbio, produção, financiamento e desenvolvimento tecnológico.

Essa introdução, ainda que rápida, procurar explicar o contexto da organização e criação do Grupo de Trabalho Catarinense de Sócioeconomia Solidária e do processo de formação do atual Fórum Catarinense de Economia Solidária.

A Economia Solidária, como veremos adiante, é permeada pela constituição de várias redes regionais, bem como de uma articulação estadual. Tal fato nos aponta, que as redes embasam, fortalecem e impulsionam a ES, dando-lhes maior possibilidade de construir a autogestão, a sustentabilidade futura, propõe a construção de políticas públicas de trabalho e renda, pois busca ir além do já estabelecido, tecendo novas relações de trabalho, cidadania e um novo projeto societário.

\section{Do Grupo de Trabalho Catarinense (GT) ao Fórum Catarinense de Economia}

\section{Solidária}

Em Santa Catarina, os empreendimentos de economia solidária vêm sendo historicamente apoiados a partir das ações de entidades que oferecem assessoria e fomento à ES em geral, organizações da sociedade civil, em especial, dos movimentos sociais, formados por associações sem fins lucrativos (ONGs), igrejas, entre outros e pela atuação das universidades, via as Incubadoras Tecnológicas de Cooperativas Populares (ITCPs) que prestam serviços de apoio e fomento para a incubação e promoção de empreendimentos solidários.

O histórico do Grupo de Trabalho Catarinense vai da I Jornada Catarinense de sócioeconomia solidária, que aconteceu em maio de 2000. A jornada foi um dos acontecimentos decisivos na história da economia solidária de Santa Catarina. Realizado em 2000, na Universidade Federal de Santa Catarina, teve papel significativo como espaço de articulação entre uma série de entidades que começaram a dar forma ao movimento de economia solidária em Santa Catarina e no Brasil de acordo com depoimento de Paul Singer, em reunião informal com representantes da CNBB-Regional Sul IV, durante apresentação de trabalho intitulado: Mini-Projetos Alternativos - construindo outra economia no Seminário sobre Políticas Públicas e Trabalho: dimensões éticas, socioeconômicas e culturais, realizado pela Universidade do vale do rio dos Sinos, em São Leopoldo, em 2005. 
Essa jornada foi organizada por pessoas de um Núcleo de Estudos e Assessoria em Empreendimentos Produtivos Populares - da UFSC, por técnicos do Centro de Estudos e Promoção da Agricultura de Grupo - CEPAGRO, pelos representantes do Fundo de MiniProjetos Alternativos, da CNBB-Regional Sul IV e pela Agência de Desenvolvimento Solidário - ADS/CUT. Dentre os objetivos dessa jornada estava o fortalecimento da articulação entre grupos rurais e urbanos na perspectiva de construir uma rede de trocas que potencializasse as experiências de economia solidária já existentes em SC.

Ressalta o participante Joaquim Melo, educador e líder comunitário, criador do $1^{\circ}$. Banco comunitário de finanças solidárias - o Banco Palma, que aquela Jornada foi um importante momento de compreensão do fenômeno da economia solidária, quando ele teve a visão de que o que eles faziam em Fortaleza não era simplesmente um banco, mas um "banco de economia solidária"; bem como também de articulação nacional:

foi durante um colóquio em Florianópolis, em maio de 200, que tive essa revelação. Surfando na Web, vi o anúncio para uma conferência sobre as moedas sociais. Ao percorrer o programa, concluí que devia assisti-lo. Talvez aí haja uma pista para dar amplidão ao Banco Palmas. Troca, intercâmbio, moeda social: em Florianópolis, onde se realiza o encontro entre universitários e atores associativos, descubro o vasto campo no qual podem entrar intercâmbios econômicos à margem do campo capitalista clássico. Assisto às conferências e travo conhecimento com marcos Arruda, um economista do PACS (Instituto de Políticas Alternativas do Cone Sul) (MELO, 2013, p. 210).

Como desdobramento da jornada, já em 2000 iniciou-se a articulação em torno da constituição de um Fórum ou grupo de trabalho de Economia Solidária em Santa Catarina. O Grupo de Trabalho (GT) nasceu então como uma organização informal, de caráter estadual, que congrega instituições da sociedade civil que atuam no desenvolvimento da economia solidária - seja no fomento, na assessoria, na articulação - e empreendimentos de economia solidária (cooperativas, associações, empresas autogestionárias, grupos informais de produção, agroindústrias familiares, etc.).

No ano seguinte, o GT organizou, em Lages a I Feira Catarinense de Socioeconomia Solidária, o que repercutiu muito na motivação para o fortalecimento do próprio GT.

Em 2002, a grande ação do GT foi à realização do Seminário Estadual, que discutiu e tirou encaminhamentos importantes acerca de temas relacionados à produção, comercialização, crédito, legislação e tributação. Como desdobramento deste seminário, o GT organiza no ano de 2003, a II Feria Catarinense de Socioeconomia Solidária realizada em 
Blumenau. Ainda neste ano de 2003, o GT ajudou na organização e desenvolvimento de uma Audiência Pública sobre a economia solidária em Santa Catarina, com o propósito de colocar o tema no dia a dia do legislativo catarinense e proporcionar o intercâmbio de informações e busca de apoio para o avanço desta nova proposta de geração de trabalho e renda no estado. Outra grande ação do GT neste ano foi à formulação de uma proposta de programa para a economia solidária apresentada ao governo do Estado.

No ano de 2004, aconteceram reuniões com a principal preocupação que norteou as discussões do GT foi a de definir uma agenda propositiva com temas prioritários para nortear a política do estado para a ES.

No início de 2005 o Grupo de Trabalho refletiu sobre sua organização apontando a necessidade da discussão sobre a mudança de denominação de Grupo de Trabalho para Fórum Estadual. Tendo presente a preocupação de facilitar o diálogo com outros fóruns estaduais e com o fórum brasileiro e não caracterizar a ideia de uma comissão de trabalho. Optou pela nomenclatura que é padrão em todo o Brasil e desta forma, a partir de 2005, o Grupo de Trabalho passou a ser chamado de Fórum Catarinense de Economia Solidária (FCES).

A realização da III Feira Catarinense de Economia Solidária em Itajaí (maio 2005) foi um mais uma ação do Fórum Catarinense de fortalecimento e articulação de ES.

O FCES buscou a unidade na diversidade, favorecendo a construção da identidade graças à prática de respeitar as contribuições diversas de cada região e especificidades das suas organizações.

O fortalecimento da economia solidária no Brasil e, em SC passa também pela sua crescente federação em redes de produção, de comercialização, de financiamento. Marcos Arruda, no texto: Rede que tecem democracia e liberdade compara a economia solidária ao gesto do pescador que lança a rede no $\operatorname{mar}^{3}$ :

Quando o pescador estende sua rede no chão ou na água, ela se deita horizontalmente, espraiada para alcançar o espaço mais amplo que puder. Nenhum nó está acima dos outros, nem é mais importante do que os outros. Nenhum nó pode pensar os outros nós como competidores, adversários ou inimigos. Cada nó sabe que, fazendo parte da rede, está indissoluvelmente ligado a quatro nós ao seu redor, que por sua vez estão ligados cada um a quatro outros nós, numa progressão exponencial para formar a rede. Portanto, cada nó tem consciência de sua responsabilidade por si próprio, pela sua ligação com os quatro nós seus vizinhos, e pela integridade de rede inteira. Cada nó sabe que é único e que os outros nós, também são únicos. É esta diversidade de nós que forma a unidade da rede. Assim é a

\footnotetext{
${ }^{3}$ Texto elaborado por ocasião da Reunião do Fórum Brasileiro de Economia Solidária, em 2005.
} 
economia solidária. Ela trata de muito mais do que a mera atividade de produzir para sobreviver... Ela convoca cada habitante a empoderar-se para ser sujeito do desenvolvimento dos seus potenciais individuais e coletivas [...] (ARRUDA, 2005).

A articulação em rede é uma das estratégias da economia solidária. Os grupos/empreendimentos de ES que se isolam têm muito mais dificuldades de sobreviver, enquanto os que se juntam a outros podem potencializar seus esforços e obter mais resultados. Para Mance ${ }^{4}$ (1999), um dos autores que têm estudado a formação de redes solidárias, as redes podem ser definidas:

[...] articulação entre diversas unidades que, através de certas ligações, trocam elementos entre si, fortalecendo-se reciprocamente, e que podem se multiplicar em novas unidades, as quais, por sua vez, fortalecem todo o conjunto à medida que são fortalecidas por ele, permitindo-lhes expandir-se em novas unidades ou manter-se em equilíbrio sustentável.

A organização em forma de rede permite a articulação social. Permite identificar e mobilizar atores, animar a organização de novos atores em rede, influir nas organizações e alianças estratégicas, abrir espaços políticos de reconhecimento da economia solidária nas esferas de poder. Para entender a economia solidária como uma é preciso identificar como são conduzidas as ações na direção do conceito propositivo de rede.

Para Sherer-Warren (2007), a organização em forma de rede deve ser constituída através de relações democráticas, com uma organização horizontalizada, participação mais equitativa, não devendo ter estruturas de poder.

O movimento da Economia Solidária se fundamenta nos valores da solidariedade, da democracia, da auto-gestão, da cooperação e da responsabilidade social. Estes são os seus princípios básicos.

Partindo-se da prática e compreendendo o movimento da economia solidária como uma rede que conecta vários nós define-se também o Fórum Catarinense de ES como parte da rede. O FCES tem como objetivo o fortalecimento da rede de economia solidária catarinense e organiza-se estrategicamente redes solidárias.

Assim, podemos entender o FCES como parte da rede a partir das dinâmicas próprias de trabalho. Percebendo os elementos básicos da rede, seus nós/células e a suas conexões.

Focar o olhar sobre a organização em rede do FCES significa conhecer os sistemas vivos, ou seja, os nós da rede; as formas de inclusão social dos nós; entender como se sustenta e se autoproduz a rede. Significa responder como é a sua complexidade organizacional? A sua

\footnotetext{
${ }^{4}$ Euclides André Mance. A revolução das redes: a colaboração solidária como uma alternativa pós-capitalista à globalização atual. Petrópolis: Vozes, 1999, p. 24.
} 
organização possibilita experiências de democracia? Como são resolvidas as tensões entre as tendências competitivas? Como buscar um consenso mínimo que permita uma gestão coletiva, transformando todos os elos da rede em agentes do capital social? Como se dão as trocas no interior da rede? Como é animada e mantida a participação dos membros na rede? Como se dão as informações? Como garantir a inclusão dos mais excluídos? Como incluir politicamente no debate público as populações mais excluídas e discriminadas? Quais as formas de trabalhos para a promoção de reconhecimento social?

\subsection{A rede: composição, objetivos e funcionamento.}

O FCES é uma organização informal que congrega instituições da sociedade civil e governamentais que atuam no desenvolvimento da economia solidária - seja no fomento, na assessoria, na articulação - e empreendimentos de economia solidária (empreendimentos econômicos solidários compreendem as organizações coletivas tais como: associações, cooperativas, empresas autogestionárias, grupos de produção, clubes de trocas, redes e centrais...) com a missão de oportunizar condições favoráveis ao fortalecimento dos empreendimentos de ES do estado de Santa Catarina. É um espaço plural e diversificado, que garante a participação e engajamento sem discriminação de crença, cultura, gerações, capacidades físicas, sexo, cor ou opção sexual. Assim busca-se a verdadeira inclusão social onde as pessoas passam de vítima a sujeito, passam a ser protagonistas.

A figura abaixo, reflete a abrangência do FCES, oferecendo uma pequena amostra de sua articulação e representação.

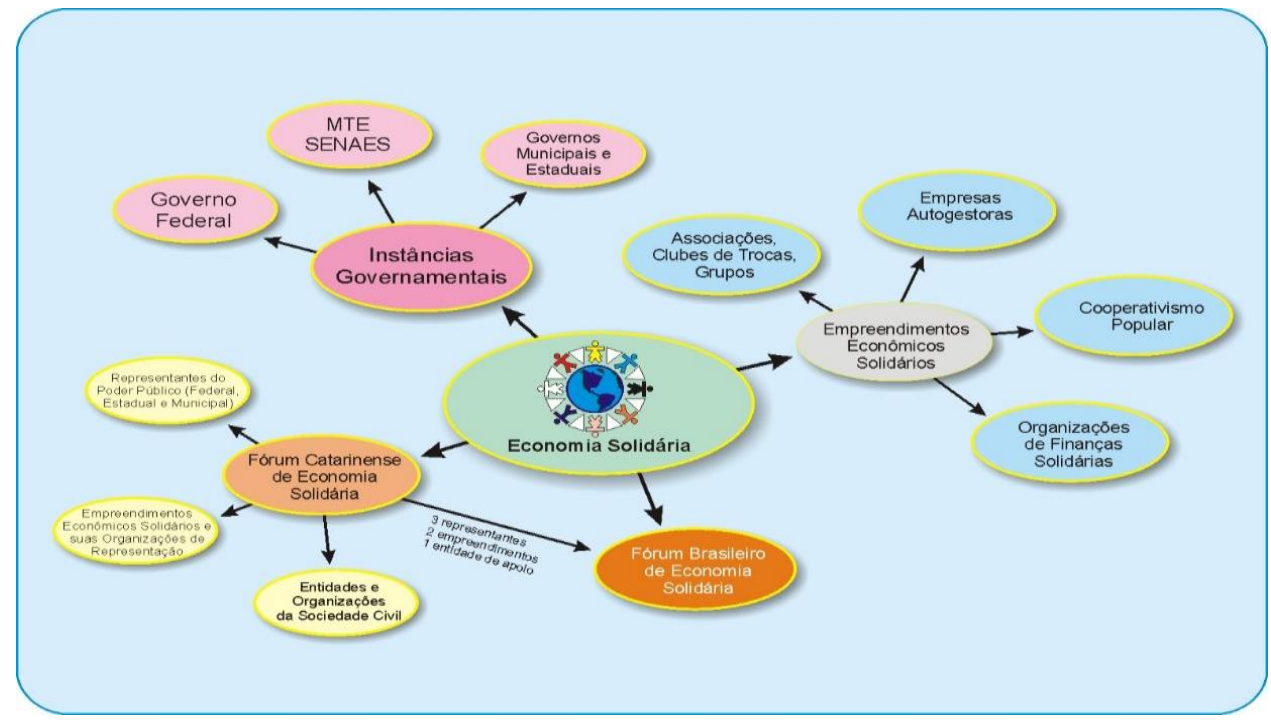


O alimento das redes á a informação, é a produção, circulação, reedição, arquivamento, a troca. Para se articular o FCES possui um e-group que serve de canal de comunicação e realiza reuniões ordinárias bimensais, e muitas vezes, extraordinárias, para dar conta dos seus objetivos e realizar o planejamento realizado a cada início de ano. Outros canais como correios, telefones, etc. também servem de auxílio no repasse das informações. Tem um sistema de arquivamento de suas produções. Porém ainda é preciso avançar para superar desafios como o de estimular e manter a conectividade dos participantes, estimular para uma cultura de compartilhamento de conhecimento, experiências, informação e ideais.

Para manter viva a rede e garantir a participação o FCES criou um processo de formação e informação descentralizado, permitindo a troca de experiências e o empoderamento de todos/as os elos. As ações são planejadas conjuntamente garantindo a descentralização e despersonificação. Assim o FCES constitui-se como um grupo que funciona como uma rede de co-responsabilidade mútua, na qual todos procuram interagir democraticamente, para fortalecimento recíproco.

O FCES se articula com o Fórum Brasileiro de ES (FBES), mediante seus representantes, e partilha dos seus princípios reafirmando: a) a pluralidade e a diversidade, garantindo a participação e engajamento sem qualquer forma de discriminação, b) a valorização social do trabalho humano, o caráter emancipatório da Economia Solidária e as práticas cujas relações são baseadas na equidade, na cooperação, na solidariedade, no resgate da dignidade e da cidadania, reafirmando a importância dos trabalhadores e trabalhadoras serem os detentores dos meios de produção e dos respectivos resultados; c) a visão de uma sociedade autogestionária na qual o desenvolvimento econômico tem como centralidade o homem e a mulher; d) na busca de uma relação de intercâmbio e integrada com a natureza, na valorização do saber local, da cultura, da tecnologia popular e da ética do consumo; e) o estimulo ao conhecimento e a cooperação entre as organizações que o integram, fomentando o desenvolvimento de cadeias produtivas locais e regionais; f) a articulação de um espaço de representação em busca do fortalecimento da ES, enquanto política pública que respeita o protagonismo e autonomia dos empreendimentos, das redes e entidades que o integram, fortalecendo o desenvolvimento local e auto-sustentável.

Para cumprir com sua missão e de acordo com seus princípios, o FCES tem como objetivos: 1. Fomentar a criação de redes, fóruns locais e/ou regionais; 2. Realizar feiras de ES; 3. Realizar seminários setoriais para definição de estratégias comuns de organização da produção, comercialização, crédito e inovação tecnológica; 4. Realizar seminários e jornadas para discussão do ideário sócio-econômico, político e cultural da economia solidária, bem 
como para troca de experiências e divulgação; 5. Promover estratégias de comercialização e divulgação dos produtos da ES, como catálogos, campanhas publicitárias, entre outros; 6. Representar o FBES no estado de Santa Catarina; 7. Discutir com o poder público estadual e federal a implementação de políticas públicas para o desenvolvimento da economia solidária.

A coordenação é assumida de forma espontânea por um conjunto de instituições e empreendimentos que participam de forma mais comprometida e constante. Através desta forma de gestão vão se constituindo outras estruturas de poder que possibilitam vivenciar relações sociais e políticas mais democráticas rompendo com as relações tradicionais, piramidais. É claro que esta organização horizontal apresenta limites e desafios que ainda precisam ser superados. Porém a vivência de outras relações está sendo construída.

Como estratégia de fortalecimento o FCES vem fomentando a constituição de fóruns regionais, como já ocorre no Vale Rio Itajaí, em Florianópolis, em Chapecó, em Criciúma e em Joinville.

Possibilitando a instrumentalização do FCES e das redes regionais para a elaboração de políticas públicas em ES a construção da proposta de Lei de Economia Solidária para o estado, que está sendo negociada com o poder público estadual, com certeza fortalece a adesão política e social, articulando os movimentos sociais com o poder público.

O FCES concretizou também, através da realização da I Conferência Estadual, o objetivo de reunir representantes dos empreendimentos solidários, dos movimentos sociais e organizações que fomentam a economia solidária e/ou se serve dela para combater a pobreza e a exclusão social e dos representantes dos governos federal, estaduais e municipais que apoiam a ES. A Conferência teve como objetivos afirmar a economia solidária como estratégia e política de desenvolvimento; propor princípios e diretrizes para orientar uma política nacional de economia solidária; identificar o estado atual e o potencial da ES tanto do ponto de vista da sua organização social quanto das políticas públicas desenvolvidas e propor prioridades e estratégias de atuação para as políticas e programas de economia solidária, bem como, os mecanismos de participação e controle social.

\subsection{Os desafios a serem superados.}

A economia solidária não é um sonho distante. Não é algo que aconteceu por decreto, nem é fruto de uma cabeça privilegiada. É um movimento amplo e profundo, cujas raízes históricas se encontram nas ações e nas lutas de organizações de trabalhadores/as, de 
movimentos populares, de grupos engajados nas universidades e na Igreja. Um movimento vivo, dinâmico, que se fortalece, se organiza e que forma uma rede.

Esta organização em rede traz desafios a serem enfrentados. Com relação à sua organicidade embora seja possível perceber vários elementos básicos da organização em rede apresentam-se alguns desafios a serem enfrentados.

Um dos maiores desafios para seja garantir que ela tenha na prática uma proposta inclusiva. A rede da Economia Solidária tem como proposta a inclusão dos grupos mais marginalizados. Esta inclusão acontece concretamente com a criação de espaços locais de discussão (fóruns regionais, com a formação de agentes locais, com a realização de feiras regionais e estaduais). No espaço dos fóruns vai surgindo uma nova cidadania, ligada a questões sociais mais amplas e diversas, reconhecendo inúmeros direitos. Porém ainda permanece o desafio de ampliar estes espaços, de tecer a rede propiciando a elaboração de uma identidade coletiva, constituída pelos integrantes em sua individualidade.

Outro desafio é a agregação. É a necessidade das redes locais se integrarem totalmente em redes regionais, as regionais em redes nacionais e até internacionais em uma rede mundial solidária. Como estratégias, procurando vencer este desafio, o FCES busca a valorização das pessoas e dos vínculos entre elas, ligações da rede, garantindo espaços para apresentação da história e da experiência dos grupos.

O desafio de descentralizar, interiorizar e territorializar ainda mais as formas de organização do FCES e suas instâncias locais (regiões, municípios e pequenas comunidades) para ser coerente com o eixo agregador da Economia Solidária, enquanto perspectiva de desenvolvimento sustentável e solidário, endógeno e local ainda está presente.

Também permanece a necessidade da extensividade, de gerar novas relações, novos nós, de incluir os excluídos/as das mais longínquas instâncias possibilitando a integração e articulação com o movimento.

A questão da sustentabilidade do FCES que é a força e sustento da rede e que depende do interesse das pessoas em comunicarem e compartilhar seus conhecimentos, seus anseios, seus objetivos e da atuação sistêmica, articulada bem como de condições financeiras para manter aparece como um grande desafio. Buscar sustento para suas ações não tem sido nada fácil. Os projetos de apoio à rede de ES nem sempre são viabilizados.

No que se refere ao fortalecimento e a criação de formas e estruturas de participação cada vez mais horizontais em redes e cadeias produtivas também se apresentam ainda alguns desafios. As atuais redes e cadeias nacionais nem sempre nascem ou se estruturam a partir de processos locais. A representação nacional nem sempre significa participação horizontal junto 
às bases de coordenação local dos Fóruns. Como buscar coerência com a perspectiva de desenvolvimento endógeno e autogestão cada vez mais em redes e cadeias horizontalizadas a partir dos territórios locais, sem perder de vista o contexto nacional e internacional?

Embora apresentando limites e desafios a serem superados é possível afirmar que o Fórum Catarinense de Economia Solidária está conectado em rede. E uma rede sólida da sociedade civil organizada que estabelece um processo político cultural, de forma horizontal e que tende ao amadurecimento político, a medida que vai criando as condições para o seu plano desenvolvimento. Desta forma, o Fórum Catarinense tem papel fundamental para o fortalecimento da economia solidária, para sua afirmação, na construção de redes, bem como na formulação de políticas públicas adequadas ao setor em Santa Catarina.

\section{CONSIDERAÇÕES FINAIS}

A consolidação da Economia Solidária vincula-se radicalmente à existência de redes. As redes interligam os grupos/empreendimentos realizando ações coletivas conjuntas, o que confere a todos um novo potencial de expansão e um aprimoramento do coletivo.

O FCES integra múltiplas experiências participativas, caracterizadas por sua diversidade de atores, pela sua configuração em redes, pelo seu reconhecimento das diferenças e sua ênfase na construção de novos valores culturais, entre os quais a solidariedade e a cooperação, mas, sobretudo, pela busca da justiça e o exercício da cidadania.

Neste sentido, o FCES pode ser compreendido como a expressão organizativa do movimento de economia solidária, no qual confluem diversos atores sociais, construindo identidades e projetos que, mesmo não sendo homogêneos, contestam e se opõem ao modelo econômico neoliberal, visando o resgate de formas coletivas de trabalho, produção e distribuição de bens e serviços, numa perspectiva da construção de uma sociedade justa, solidária e igualitária.

A experiência aponta os desafios e as potencialidades desse tipo de organização em rede, que poder ter especificidades e peculiaridades, porém reafirma a força do coletivo, a riqueza da troca, os ganhos da cooperação e o poder de mobilização no enfrentamento das várias faces da exclusão social. É um ensaio para uma outra economia possível parafraseando Paul Singer.

\section{REFERÊNCIAS}


ARRUDA, Marcos; QUINTELA, Sandra. Economia a partir do coração. In: SINGER, Paul; SOUZA, André Ricardo de. A economia solidária no Brasil: autogestão como resposta ao desemprego. 2. ed. São Paulo: Contexto, 2003.

BRASIL. Ministério do trabalho e Emprego. Atlas da Economia Solidária no Brasil 2005. Brasília: MTE, SENAES, 2006.

CONFERÊNCIA NACIONAL DE ECONOMIA SOLIDÁRIA, 1., 2006, Brasília: MTE, SENAES, SPPE, DEQ, 2006.

CATTANI, Antonio David (org). A outra economia. Porto Alegre: Veraz, 2003.

CERIS. Obras sociais da Igreja Católica: atividades das instituições socioeducativas e das paróquias. São Paulo: Loyola e Anamec, 2000.

LECHAT, Noelle Marie Paule. As raízes históricas da economia solidária e seu aparecimento no Brasil. Ijuí, RS: Ed. Unijui, 2006. (Cadernos Unijuí: Série Economia Solidária, 1).

LISBOA, Armando de Melo. Os desafios da Economia Popular Solidária. Cadernos do CEAS, Salvador, n. 189, p. 51-67, 2000.

MAGALHÃES, Reginaldo Sales. A nova economia do desenvolvimento local. 2000 (trabalho mimeo).

MANCE, Euclides André. A revolução das redes: a colaboração solidária como uma alternativa pós-capitalista à globalização atual. Petrópolis: Vozes, 1999.

NOGUEIRA, Vera Maria Ribeiro. Planejamento de Políticas Públicas. Cadernos de Textos CRESS, Florianópolis, n. 4, 1998.

PEDRINI, Dalila Maria. Entre laços e nós, associativismo - autogestão - identidade coletiva: a empresa alternativa de produção socializada de Brusque - SC. Orientadora: Silva, Maria Lucia Carvalho da. 1998. 314 f. Tese (Doutorado em serviço social) - Pontifícia Universidade Católica de São Paulo, São Paulo, 1998.

POLETTO, Ivo (org.). Solidariedade: novo caminho da paz. Brasília: Cáritas Brasileira, 1999.

POLI, Odilon. Leituras em movimentos sociais. Chapecó: Grifos, 1999.

SANTOS, Boaventura Sousa (org.). Produzir para viver: os caminhos da produção não capitalista. Rio de Janeiro: Civilização Brasileira, 2002.

SCHERER-WARREN, Ilse. Rede sociais e de movimentos. In: FERRARO JÚNIOR, L. A. (org.) Encontros e caminhos: formação de educadoras(es) ambientais e coletivos educadores. Brasilia DF: Ministério do Meio Ambiente - MMA, 2007. v. 2.

SCHERER-WARREN, Ilse. Das mobilizações às redes de movimentos sociais. Revista Sociedade e Estado, Brasília, v. 21, n. 1, jan./abr. 2006. 
SINGER, Paul. Economia solidária: geração de renda e alternativa ao liberalismo. Revista Proposta, Rio de Janeiro, n. 72, mar./maio 1997.

THEIS, Ivo. Planejamento no Desenvolvimento Regional: alternativas sustentáveis para o Médio Vale do Itajaí. REDES, Santa Cruz do Sul, v. 4, nº 1, jan./abr. 1999. 